\title{
GRUNDTVIG-LITTERATUR 1954
}

\author{
En bibliografisk oversigt ved cand. mag. Steen Johansen.
}

\section{Bibliografi.}

Steen Johansen: Bibliografi over N. F. S. Grundtvigs skrifter. IV. Rettelser og tilføjelser. Register. 1954. (308 s.).

Anmeldt bl. a. af følgende: S. H. (o: Soren Holm) i Bogens Verden 1954, 291; Chr. Kirchhoff-Larsen i Børsen 27. juni 1954; Will. Michelsen i Lychnos. Lärdomshistoriska samfundets årsbok 1954-55 (Uppsala 1955), 318; N. J. R. ( ( : Rald) i Præsteforeningens Blad 9. juli 1954; Vagn Riisager i Krist. Dagbl. 6. sept. 1954; Peter Rohde i Information 9. juli 1954; Helge Toldberg i Nationaltidende 8. sept. 1954. - Hele værket anm. af Jens Nyholm (paa engelsk) i Scandinavian Studies vol. 27, no. 3, aug. 1955 , p. $167-169$.

Steen Johansen: Om Grundtvig-bibliografiens tilblivelse.

Gr.-Studier 1954, 7-21.

Steen Johansen: Grundtvig-litteratur 1952. En bibliografisk oversigt.

Gr.-Studier 1954, 109-115.

Grundtvig-registreringen.

Gr.s håndskrifter skal registreres.

Højskolebl. 30. apr. 1954.

Om registreringen, se ogsaa G. Albeck's artikel i III i det flg. samt det i IV q omtalte referat af Gr.-Selskabets aarsmøde 1954 (i Krist. Dagbl.).

\section{Grundtvig-udstillingen.}

I samarbejde med det kgl. Bibliotek arrangerede Gr.-Selskabet en udstilling af bøger og manuskripter af $\mathrm{Gr}$., desuden billeder og genstande i tilknytning til Gr.s liv m. v., $i$ det kgl. Bibliotek 8.-26. maj 1954. Udstillingen indledtes om aftenen den 7. maj kl. 19 med en aabningshøjtidelighed (i d. kgl. Bibl.s læsesal) for indbudte gæster, hvor bl. a. prof. Fr. Bull, Oslo, talte om Gr. og Bjørnson. - - Notitser og artikler om denne udstilling, se bl. a. Højskolebl. 9. apr., Nationaltid. 8. maj, Menighedsbl. 9. maj, Krist. Dagbl. 10. maj, Politiken 11. maj (af Kai Friis Møller), Frederiksborg Amtstid. 12. maj, Præsteforeningens Blad 14. maj, Højskolebl. 4. juni 1954. 
II. Udgivelser, optryk.

Urban Schrøder (red.): Danske Prædikener gennem Tiderne. Udg. med bistand af Hal Koch. 1954. - 328 s. - Heri s. 186-199 trykt (forkortet) Gr.s præd. 11. sønd. e. Trin., fra Christ. Præd. ell. Søndags-Bog III, 1830, 470-490. - S. 200-204 præd. skærtorsdag 1851 (fra Gr.s Vartovs-Præd., 1924, 290-293). - S. 205-209 præd. paaske-sønd. 1860 (fra samme 508 $-511)$.

\section{Samlede fremstillinger, karakteristikker, mindeartikler; Gr.-forskning $i$ alm.}

Litteraturen i Danmark - og de øvrige nordiske lande. Hvem skrev hvad før 1914. Red. af Henning Fonsmark. (Politikens litteraturbøger). 1954. Heri om Gr. ved Oluf Friis 64 f. - Desuden en biografi 216-218 (m. portrætter). - I afsnit III (309 ff.) referater af indholdet af flere af Gr.s hovedvaker.

Gustav Albeck: Gamle Gr. jubilerer.

Jyllandsposten 5. juli 1954. - I anledn. af 100-aaret for Gr.s litt. debut 1804. Heri ogsaa om Gr.-forskningen og Gr.-registreringen. - Hertil $H$. Lund Hansen s.st. 11. juli, med svar fra Helge Toldberg s.st. 16. juli.

R. Anker-Moller: Et foredrag, som ikke blev holdt paa Gr.s fødselsdag. Aalborg Amtstid. 3. nov. 1954.

Henning Hoirup: Fra grundtvigfeber til grundtvigforskning. (Radioforedrag 12. apr. 1954).

Menighedsbl. 9. maj 1954. (Som antydet først holdt som foredrag i radioen, i serien: Nye perspektiver - i videnskab og kunst).

Holbergs kirkehistorie blev Gr.s A B C!

Holbæk Amts Venstreblad 10. sept. 1954. - Referat af foredrag af forstander Jorgen Jessen, Vallekilde, i Holbæk Højskoleforening 9. sept. Om Gr. i det hele, hans syn etc.

P. M. Mitchell: Dansk Litteratur i Udlandet.

Berl. Tidende 17. sept. 1954. - Heri ogsaa om kendskab til Gr.s værker i udlandet.

Helge Toldberg: Grundtvig. An Introduction by P. G. Lindhardt, . . London 1951. - Recension i Orbis Litterarum IX (1954), 247-249.

Helge Toldberg: Dansk klovneri.

Dagbladet (Oslo) 11. okt. 1954. - Svar paa E. Smith's anmeldelse s.st. af J. Kruuse: Gentagelser (1954). - Heri ogsaa om Gr.

IV. Specialia vedrorende Gr.s liv og forfatterskab.

a. Slægt; forhold til slægtninge.

Paul Nedergaard: 100 danske præsteslægter. En lille slægtshaandbog opstillet i uddrag af stamtavler. 1954. (Særhefte - m. egen paginering - af sammes: En dansk præste- og sognehistorie). 99 s. - Heri 41-42 om slægten Gr. 
Artikel om Gr.s slægt (forfædre) i Nykøbing S. (baseret paa skoleinspektør Anton Birch's undersøgelser) samt referat af afsløring d. 16. sept. 1954 af mindeplade for Gr.-slægten paa Landmandsbankens bygning, Algade 48, Nykøbing S., hvor slægtsgaarden laa, - endvidere referat (efter afsløringen) af mindegudstjeneste ved biskop Gudmund Schiøler, hvor ogsaa Anton Birch talte.

Holbæk Amtstidende 17. sept. 1954; en anden fremstilling, se Holbæk Amts Venstreblad 17. sept. 1954. - En kort omtale, se Berl. Aftenavis 18. sept. 1954.

Uffe Hansen: Fra Egebjerggaard.

Holbæk Amts Vestreblad 2. jan. 1954. - Om Gr.s slægt paa Egebjerggaard, især om Gr.s moder.

Aage Lambert-Jensen: Marie Toft paa Rønnebæksholm, der blev N. F. S. Gr.s Hustru.

Næstved Tidende 8. juli 1954.

Litt. om Fr. L. Grundtvig i anledn. af 100-aaret for dennes fødsel 1854 registreres ikke i nærv. oversigt.

\section{b. Privatliv, personlig udvikling.}

Jens Rolighed: 》Julemorgen var mit himmerig«.

Aalborg Amtstid. 24. dec. 1954. - Om Gr.s barndom.

Johs. Feveile: I har og en sådan stjerne - ! Et julepræludium over et gammelt tema.

Indre Missions Tidende 1954, 665-667 (jule-nr.). - Halvt digterisk skildring af Gr. som dreng i Tyregod samt af hans krise 1810.

Steen Johansen: Gr. og teatret endnu engang.

Gr.-Studier 1954, 96-97.

Om Gr. som præst $i$ Udby, se Paul Nedergaard: Dansk præste- og sognehistorie ... II. Rolskilde stift. 1951-54, 725-727. - I Præstø, se s.st. 695 f. Om Marie Toft og Gr., se s.st. 644-646.

Adjunkt (senere provst) D. P. Smith's erindringer om Gr., især paa landemodet $i$ Roskilde 1811, se Fra Københavns Amt (Aarbog udg. af Hist. Samf. f. Kbh.s Amt) 1954, 49-51 (ved Fanny Fang; nu uforkortet gengivet). - Jf. Politiken 13. juni 1954.

Bjorn Kornerup: Gr. i den grundlovgivende Rigsforsamling.

Kirkehist. Saml. 7. rk., bd. II, 279-280.

Henry Kaiser: En Paaske i Vartov.

Vendsyssel Tidende 11. apr. 1954. - Om Gr.s sindssygdom 1867.

Carl Weltzer: N. F. S. Gr.s sidste Fest.

Kirkehist. Saml. 7. rk., bd. II, 91-170. - Her gengives (kommenteret) Niels Lindbergs udførlige skildring af Gr.s død og jordefærd m. v.

c. Litterært eller personligt forhold til enkeltpersoner - eller disses forhold til Gr.; sammenstillinger mellem Gr. og andre.

C. Bartholdy: Gr. og Brunner.

Indre Missions Tidende 11. apr. 1954 (fortsat 18. og 25. apr., 2., 9., 16. og 23. maj; udgjorde en artikelserie m. hovedtitlen: Er Folkekirken en borgerlig Indretning? Den første af artiklerne fremkom 4. apr., hvori intet om Gr.). - Hertil Fr. Schrøder i Højskolebl. 28. maj 1954. 
Soren Holm: Gr. und Kierkegaard. Parallelen und Kontraste.

Zeitschrift für systematische Theologie 1954, 158-176.

Gr. og Chr. Molbech, se Morten Borup: Christian Molbech, 1954, jf. hertil Steen Johansens Gr.-bibliogr. IV, 122.

\section{d. Teologiske, filosofiske og psykologiske sporgsmaal vedr. Gr. \\ (Alfabetisk efter forff.; saaledes ogsaa i de flg. grupper.)}

Henning Høirup: Fra døden til livet. Gr.s tanker om liv og død. 1954. Skrifter udg. af Gr.-Selskabet VII. - 112 s.

Anmeldt bl. a. af flg.: P. Augustinus i Menighedsbl. 15. aug. 1954; Th. Balslev i Gr.-Studier 1955, 98-100; J. Bukdahl i Politiken 15. sept. 1954 og i Dansk Udsyn 1955, 192 f.; P. Hansen i Vejle Amts Folkebl. 10. juli 1954; Carl Hermansen i Aalborg Amtstid. 2. sept. 1954; S. H. (o: Soren Holm) i Bogens Verden 1954, 291; Jorgen Jensen i Bavnen 28. okt. 1954; Peter P. Rohde i Information 12. aug. 1954.

Johannes Knudsen: Gr. and American Theology Today.

Lutheran World, Winter 1954/55. Vol. I, No. 4, p. 277-287.

\section{e. Litterære eller filologiske behandlinger af dele af Gr.s forfatterskab bortset fra salmerne.}

Gustav Albeck: 》Strandbakken ved Egeløkke« og 》Havet«. Textkritiske Studier $i$ et Par af Gr.s Ungdomsdigte.

Gr.-Studier 1954, 22-39.

Hans Degen: Et Gr.-digt fra Egelykke-Tiden. En skitse.

Kirkehist. Saml. 7. rk., bd. II, 256-264.

Referat af tale af forstander Jorgen Jessen, Vallekilde, om Gr. som historiker. Holbæk Amts Venstreblad 20. sept. 1954.

Johannes Knudsen: Gr. and Mythology.

The Lutheran Quarterly Vol. VI, Nov. 1954, No. 4, p. 299-309.

Niels Kofoed: Gr. som selvbiograf. Med særligt henblik paa tidsrummet 1800 -1810. 1954. - Skrifter udg. af Gr.-Selskabet VIII. - 136 s.

Anmeldt bl. a. af flg.: Gustav Albeck i Jyllandsposten 9. sept. 1954; Jorgen Bukdahl i Politiken 20. dec. 1954; S. H. (॰: Soren Holm) i Bogens Verden 1954, 542 f.; Henning Høirup i Aalborg Amtstid. og Fyns Tid. 13. okt. 1954; Vejle Amts Folkebl. 23. dec. 1954; N. P. J. i Langelands Folkebl. 2. okt. 1954; N. Noigaard i Præsteforeningens Blad 5. nov. 1954; Vagn Riisager i Krist. Dagbl. 12. okt. 1954; Peter P. Rohde i Information 10. dec. 1954; Paul V. Rubow i Berl. Aftenavis 6. okt. 1954.

William Michelsen: Tilblivelsen af Gr.s historiesyn. Idehistoriske studier over Gr.s Verdenskrøniker og deres litterære forudsætninger. I-II. 1954.Skrifter udg. af Gr.-Selskabet VI. - 367 s.; disputats. Doktorhandlingen fandt sted 6. apr. 1954.

Anmeldt bl. a. af flg.: P. Augustinus i Menighedsbl. 16. maj 1954; Ernst J. Borup i Højskolebl. 23. apr. 1954 (m. referat af oppositionen ved doktorhandlingen; hertil $W$. Michelsen s.st. 14. maj); Jorgen Bukdahl i Politiken 14. juni 1954 og i Dansk Udsyn 1955, 196-199; Ernst Fink i Høng Husmandsskole. Julen 1954, 6-10 (Gr.s arv og efterklang) og i Tidskrift för svenska folkhögskolan 1954, 207-211; R. G. (o: Gandrup) i Aarhuus Stiftstid. 6. apr. 1954; Villiam Gronbæk i Jyllandsposten 7. apr. 1954; S. H. (o: Soren Holm) i Bogens Verden 1954, 185 f.; Chr. Kirchhoff- 
Larsen i Børsen 6. apr. 1954; Th. Krogholt i Fyns Tidende 28. maj 1954; Georg Landberg i Lychnos. Lärdomshistoriska samfundets årsbok 195455 (Uppsala 1955), 399-401; Asger Nyholm i Vestkysten 22. apr. 1954; Peter P. Rohde i Information 5. apr. 1954; Paul V. Rubow i Berl. Aftenavis 7. apr. 1954 (R.s opposition ved doktorhandlingen).

C. S. Nygaard: Romantik og kristendom.

Sorø Amtstid. 20. apr. 1954. - Især om Gr.s Thorvaldsen-digt 1844, iøvrigt om Gr. 1844 og Gr. som kristen.

August F Schmidt: Gr. i Sproghistorien.

Fyns Venstreblad 26. febr. 1954. - Betragtninger m. udgangspunkt i behandlingen af Gr.s sprog i P. Skautrups sproghistorie III, 1953.

Helge Toldberg: Gr. og den danske Rimkrønike.

Gr.-Studier 1954, 40-95.

f. Gr.s salmer.

1.

Om salmerne i alm.

Uffe Hansen: Af salmesangens historie. X. Thomas Kingo.

Menighedsbl. 19. sept. 1954. - Heri berøres ogsaa Gr.s forhold til Kingos salmer, forskellen i begge digteres livssyn etc.

P. E. Rynning: Salmediktningi i Noreg. I-II. Oslo 1954. - I bd. II, som behandler tiden efter 1814, ogsaa om Gr. som salmedigter og om indførelsen af hans salmer i Norge.

Enkelte salmer.

Uffe Hansen: Hvordan skal vi lønne Herren?

Roskilde Stiftsblad 1954, 52-53. - Bl. a. om Gr.s salme 》Jesus! at du blev min Broder! $\ll$

Uffe Hansen: En Gr.-salme i den nye Salmebog.

Nationaltidende 7. marts 1954. - Om »Lyksaligt det Folk, som har Øre for klang herovenfra«.

Aage Jespersen: Kingo-Grundtvig. I-II.

Præsteforeningens Blad 30. apr. og 7. maj 1954. - Heri især om forholdet mell. Kingos »Hvor dejlig skal Guds Kirke staa《 og Gr.s omdigtning af samme (m. samme forstelinie).

Thorvald Laursen: »Velkommen igen, Guds engle smaa - «. Da salmen blev til. Sorø Amtstid. 24. dec. 1954.

A. Bartholdy Moller: Omkring en Salme af Gr.

Vejle Amts Folkebl. 17. marts 1954. - Bl. a. om »Herrens Røst, som aldrig brister«.

S. Nielsen: Kimer, I klokker.

Aalborg Stiftstid. 22. dec. 1954.

A. Poulsen: Krist stod op af Døde!

Vejle Amts Folkebl. 17. apr. 1954.

August F. Schmidt: Dejlig er den himmel blaa.

Aarhuus Stiftstidende 18. dec. 1954. 
August F. Schmidt: Dagvisen.

Vestkysten. Tillæg. 20. dec. 1954. — Om »Den signede Dag ...«.

Vilh. Strange-Hansen: Menneske først og kristen så.

Roskilde Stiftsblad 1954, 116-117. —. Om »Lyksaligt det Folk, som har Øre for Klang herovenfra«.

Mindre bladartikler om visse Gr.-salmers optagelse i eller udeladelse af den ny salmebog er ikke medtaget her. - Enkelte oplysninger om Gr.-sange eller -salmer i Folkehøjskolens sangbog, se Poul Dam i Dansk Udsyn 1954, 126-147.

g-k. Gr. og England; Gr. som politiker; Gr. og Sonderjylland; Gr. og Vartov; Gr. og det folkelige.

Frode Aagaard: Gr. og junigrundloven.

Aalborg Amtstid. 4. juni 1954.

H. Lund Hansen: Hvad Gr. saa - og ikke saa - i England.

Fyns Venstreblad 12. juni 1954.

H. Østergaard-Nielsen: Ansvar og Folkelighed.

Julebogen. Udg. af Kirkeligt Samfund af 1898. 1954, 72-88. Heri s. $80 \mathrm{ff}$. om Gr.

Svend Zachariassen: Gr.s Indflydelse paa Kunsten i Danmark.

Vartovbogen 1954, 11-35.

1. Gr.s skoletanker, Gr. og højskolen (folkeoplysningen), Gr. og Norden. (Udvalg.)

Frode Aagaard: Det folkelige foredrag.

Fyns Tidende 17. sept. 1954. - Bl. a. om Gr.s foredragsvirksomhed.

Jorgen Bukdahl om Gr.s Gøteborg-tanke, se Dansk Udsyn 1954, 249 f.

Chr. Christensen: Højskole eller noget andet.

Randers Dagblad 27. okt. 1954.

H. Engberg-Pedersen: Højskolens Opbrud.

Berl. Tid. 16. nov. 1954.

Lad bare Gr. køre paa Knallert! Interview med forstander J. Kr. la Cour Madsen om det folkelige oplysningsarbejde.

Svendborg Avis 8. nov. 1954. - Hertil Vagn Christensen i VejstrupBogen 1954, 11-15.

Olav S. Midttun: Bjørnstjerne Bjørnson og folkehøyskolen. Oslo 1954. $141 \mathrm{s.}$

Heri ogsaa om Bj. og Gr. og den danske folkehøjskole.

Harald Petersen: Højskolen i Tidens Strøm.

Aarsskrift for Ask-Elever. 1954, 17-22.

Hans Thysen. Højskolens mørkemænd.

Krist. Dagbl. 4. aug. 1954.

Chr. Winther: Højskolens fremtid.

Vestkysten 24. marts 1954.

m. Gr. og det menneskelige, det sociale. 
$\mathrm{n}-\mathrm{o}$. Grundtvigianismen (som kirkelig retning); Gr. og missionen. (Udvalg.)

Peder Bukh: En grundtvigsk Vækkelsesbevægelse paa Aarhusegnen.

Aarhus Amtstidende 17., 23., 30. juni, 28. juli 1954.

Jacob Busk: Ensomhed og fællesskab.

Sorø Amtstid. 11. nov. 1954. - Referat af det grundtvigske vennemøde paa Snoghøj.

Carl Hermansen i Menighedsbladet 31. okt. 1954 i »Redaktørens ugebrev《 om tidligere opfattelse (især hos biskop G. P. Brammer) af grundtvigianismen som et »parti《, en »sekt«. Hertil K. P. Mikkelsen s.st. 12. dec. og C. H.s svar i samme nr.

Halfdan Hogsbro: Dansk Kirkeliv i Amerika.

Berl. Tidende 12. nov. 1954. - Heri ogsaa om grundtvigianismens kaar i U.S.A.

Den danske Kirkes Historie. Under Redaktion af Hal Koch og Bjørn Kornerup. VI. 1954. Tiden $1800-1848$ af Hal Koch. - 365 s. - Heri den unge Gr. behandlet s. 155-174; Gr.s kirkekamp 221-233; grundtvigianismen $235 \mathrm{ff}$.

Arne Brandt Pedersen: Om vækkelsen i Vendsyssel.

Vraa Højskoles Aarsskrift 1954, 3-8. - Om den gr.-ske vækkelse i Vendsyssel i det 19. aarh., bl. a. om Skov-Kirsten og Bertel Henriksen. Om grundtvigianismens stilling til Lindhardt-debatten om »det evige liv«, se interview med biskop Gudmund Schiøler i Nationaltidende 26. sept. 1954.

A. Pontoppidan Thyssen: Det grundtvigske Møde i Middelfart 1891 og dets Forudsætninger. Bidrag til Belysning af den gammelgrundtvigske Retning.

Kirkehist. Saml. 7. rk., bd. II, 171-230. - Hertil Fr. Schroder i Menighedsbladet 4. apr. 1954 (Af Kirkeligt Samfunds forhistorie).

\section{p. Grundtvigianere.}

I. Bjerregaard-Petersen: 50-aarigt grundtvigsk menighedsjubilæum i Aarhus. Demokraten 5. sept. 1954.

Jens Futtrup: Nordmanden Ole Vig. - Se under Tilføjelser i slutn. af nærvær. oversigt.

Anker Jensen: Wilhelm Andreas Wexels.

Præsteforeningens Blad 5. marts 1954.

P. G. Lindhardt: En dansk sognepræst. Morten Pontoppidan. 1954. 161 s. Hertil P. Bukh i Højskolebl. 27. aug. 1954.

P. G. Lindhardt: De ædles æt . .

Politiken 26. nov. 1954. - Mindeartikel i anledn. af 100-aaret for F. F. Falkenstjernes fødsel.

Paul Nedergaard: Dansk præste- og sognehistorie. .. II. Roskilde stift. 195154. - Heri ogsaa behandlet talrige fremtrædende grundtvigianere, fx. F. E. Boisen, J. F. Fenger, Carl Koch, Peter Rørdam, se bogens personregister. - Jf. IV b her foran.

C. S. Nygaard: Pinsetiden i den grundtvigske Menighed.

Højskolebladet 4. juni 1954. - Heri om den første generation af grundtvigske præster, især V. Birkedal, P. Rørdam.

Om Vilh. Birkedal som forfatter til en salme, se P. Poulsen: Salmebogen fortæller. 1954, 124-132.

Henri Werring: Lars Eskeland. Læreren og mennesket. Oslo. $1954-150$ s. 
q. Grundtvig-Selskabet og dets publikationer.

Gr.-Selskabet har i 1954 udsendt følgende skrifter:

Grundtvig-Studier 1954. Under redaktion af Gustav Albeck. - 116 s.

Anmeldt bl. a. af flg.: Jorgen Bukdahl i Politiken 20. dec. 1954; N.P.J. i Langelands Folkeblad 2. okt. 1954; Th. Krogholt i Fyns Tidende 29. okt. 1954; Christian Nielsen i Sorø Amtstidende 18. okt. 1954; Vagn Riisager i Krist. Dagbl. 12. okt. 1954; Peter P. Rohde i Information 10. dec. 1954; Paul V. Rubow i Berl. Aftenavis 6. okt. 1954: Holger Sorensen i Menighedsbladet 19. dec. 1954.

I Gr.-Selskabets serie »Skrifter udgivet af Grundtvig-Selskabet《 er i 1954 udsendt:

Bd. VI. William Michelsen: Tilblivelsen af Gr.s historiesyn.

Anmeldelser, se IV e her foran.

- VII. Henning Høirup: Fra døden til livet. Gr.s tanker om liv og død. Anmeldelser, se IV d her foran.

- VIII. Niels Kofoed: Gr. som selvbiograf. Anmeldelser, se IV e her foran.

Referat af Gr.-Selskabets aarsmøde 22. okt. 1954, se Krist. Dagbl. 23. okt. 1954. - Se ogsaa Højskolebl. 29. okt. 1954.

Tilføjelser til tidligere oversigter over Gr.-litteratur.

Til oversigten over litt. 1952 ( $i$ Gr.-Stud. 1954) tilføjes:

Ad IV p: Ernst J. Borup: Højskoleforstander Alfred Povlsen, Ryslinge. 1952. Kirkeligt Samfunds Forlag. - 114 s.

Til oversigten over litt. 1953 (i Gr.-Stud. 1955) tilføjes:

Ad II: Et brev fra Gr. til Oehlenschläger 1812 (og svarbrev fra Oehl.) er tr. i: Breve fra og til Adam Oehlenschläger 1809-29. I (1953), 73-76, med Oehl.s svar $76-80$.

Ad III: Johannes Knudsen: Grundtvig Research.

The Lutheran Quarterly, Vol. 5, May 1953, No. 2, p. 167-174.

Ad IV d: Vagn Hansen: La conception ecclésiologique de N. F. S. Grundtvig. Dieu Vivant. Vol. 25 (1953), p. 143-146.

Ad IV h: Sven Clausen: De danske statsteorier. 1953. - Heri om Gr.s politiske anskuelser 213-216.

Ad IV l: Uffe Grosen: Noget om folkeoplysningen! Tale ved elevmødet 1953. Fra Vallekilde Folkehøjskole 1953, 16-26.

Ad IV p: Torstein Hoverstad: Ole Vig. Ein norrøn uppsedar (॰: opdrager). Hamar 1953. - 447 s. - Hertil Jens Futtrup i Højskolebladet 30. apr. 1954 (Nordmanden Ole Vig).

Ad IV p: Her tilføjes s. 118, lin. 11 f. o.: og samme i Samtiden 1954, 308-326. 